\title{
Comparison of effectiveness for fluoroscopic cervical interlaminar epidural injections with or without steroid in cervical post-surgery syndrome
}

\author{
${ }^{1}$ Pain Management Center of Paducah, Paducah, Kentucky, \\ ${ }^{2}$ Massachusetts General Hospital and Harvard Medical School, Boston, MA, USA \\ Laxmaiah Manchikanti ${ }^{1}$, Yogesh Malla ${ }^{1}$, Kimberly A Cash ${ }^{2}$, Vidyasagar Pampati ${ }^{2}$, and Joshua A Hirsch ${ }^{2}$
}

Background: Neck and back pain are leading sources of disability placing substantial burden on health care systems. Surgical interventions in managing chronic neck pain secondary to various disorders continue to increase. Even though surgical interventions are effective, a significant proportion of patients continue to have symptomatology and develop cervical post-surgery syndrome. This study was performed to know the effectiveness of cervical interlaminar epidural injections with or without steroids.

Methods: The effectiveness of fluoroscopic cervical interlaminar epidural injections in post-surgery syndrome was evaluated in a randomized, active controlled trial. The study population included 116 patients assigned to 2 groups. Group 1 received cervical interlaminar epidural injections with local anesthetic alone and Group 2 received injection with local anesthetic and steroids. The main outcomes were defined as significant improvement (greater than 50\%) of pain relief using the numeric rating scale and/or functional status improvement using the Neck Disability Index (NDI).

Results: Both groups had similar results with significant improvement ( $\geq 50 \%$ pain relief and functional status improvement) in 69\% of the patients in Group I, whereas, in Group II, 71\% of the patients showed significant improvement at the end of 2 years. During a 2-year period, the average number of procedures was 5 to 6 , with an average of approximately 12 weeks of significant improvement per procedure.

Conclusions: Fluoroscopic cervical interlaminar epidural injections administered in cervical post-surgery syndrome using local anesthetic, regardless of the use of steroids, may be effective in approximately $70 \%$ of the patients at 2-year follow-up. (Korean J Pain 2018; 31: 277-88)

Key Words: Back pain; Cervical vertebrae; Chronic pain; Epidural injections; Follow-up studies; Local anesthetics; Neck pain; Postoperative complications; Reoperation; Steroids.

Received September 6, 2018. Accepted September 16, 2018

Correspondence to: Laxmaiah Manchikanti

Pain Management Center of Paducah, 2831 Lone Oak Rd, Paducah, KY 42003, USA

Tel: +1-270-554-8373, E-mail: drlm@thepainmd.com

() This is an open-access article distributed under the terms of the Creative Commons Attribution Non-Commercial License (http:// creativecommons.org/licenses/by-nc/4.0/), which permits unrestricted non-commercial use, distribution, and reproduction in any medium, provided the original work is properly cited.

Copyright (C) The Korean Pain Society, 2018 


\section{INTRODUCTION}

Neck and back pain are a leading source of global disability with a substantial burden on health care systems and society, with loss of productivity and a consumption of a large proportion of health care resources [1].

Dieleman et al. [2,3], in assessing personal spending on personal health care and public health in the United States from 1996 to 2003, showed yearly spending of $\$ 87.6$ billion for low back and neck pain and an additional $\$ 95.9$ billion in managing musculoskeletal disorders. The expenses for low back and neck pain accounted for the third highest amount. The "state of United States health" from 1990 to 2016 described the burden of diseases, injuries, and risk factors, and showed that morbidity and chronic disability now account for nearly half of the United States health burden, despite substantial progress and improvement in health $[4,5]$.

The studies also have shown that among the 30 leading diseases and injuries contributing to years lived with disability in 2010 in the United States, neck pain ranked number 3 , with low back pain ranking as number one, followed by other musculoskeletal disorders ranking as number 2. Depression was number 4, and anxiety disorders ranked as number 5 [4].

In addition, the estimates of regional pain in the spine also have shown neck pain ranking as number 2 with 32\% prevalence, preceded by low back pain with the highest prevalence, at $43 \%$, followed by the lowest prevalence in the thoracic spine [6]. Studies of the global burden of neck pain and disability have shown a point prevalence of neck pain at $4.9 \%$, with a significant proportion of patients suffering from chronic neck pain and arm pain with a high disability index [7].

Chronic persistent neck pain may be secondary to a multitude of degenerative spine pathologies including disc herniation, cervical spondylosis, and spinal stenosis with multiple modalities of treatment ranging from over the counter medication to complex surgical fusions [8-21]. Surgical interventions have been increasing rapidly, for some disorders as much as 7-fold [14-17]. The outcomes with surgical interventions are sometimes associated with failure and also requiring repeat surgery with a rate of $13.4 \%$ to $32 \%[16,21]$. However, many patients are not candidates for surgery, nor are they willing to undergo extensive surgical interventions after failure of the initial surgical interventions [15,21].

Consequently, many patients may suffer with cervical post-surgery syndrome, which presents as a cluster of symptoms with persistent chronic axial pain, with or without radiculitis, with stenosis, spondylosis, recurrent disc herniation, facet joint pain, and epidural scarring.

Cervical epidural injections have been utilized for managing the chronic pain of cervical post-surgery syndrome in only one manuscript presenting preliminary results that were encouraging [22]. However, cervical interlaminar epidural injections have been studied more frequently in disc herniation and occasionally in spinal stenosis, but rarely in pain of discogenic origin [23]. Thus, the evidence for cervical interlaminar epidural injections in managing post-surgery syndrome is preliminary, and continues to be the subject of debate at best, along with all other epidural injections, including those administered to manage radiculopathy in the cervical and lumbar spine $[23,24]$. The majority of the cervical interlaminar epidural injections performed in controlled settings were active controlled trials with successful results [23], showing no significant difference between local anesthetic or local anesthetic with steroids. There have been frequent multiple studies performed on low back pain of effectiveness and cost utility analysis in the lumbar spine [23-26] for epidural injections and facet joint interventions, and occasionally in the cervical spine [20,23,27], showing significant evidence of effectiveness and cost utility.

The present assessment of a 2-year follow-up of cervical interlaminar epidural injections in managing chronic neck pain of cervical post laminectomy syndrome is a continuation of a previously published preliminary report of one-year follow-up, including a total of 56 patients [22]. The study included a total of 116 patients with 58 patients in each group, completing 2-year follow-up with local anesthetic alone or with local anesthetic and steroids.

\section{MATERIALS AND METHODS}

This study was conducted based on Consolidated Standards of Reporting Trials (CONSORT) guidelines (www. consort-statement.org/). The study was approved by the Institutional Review Board (IRB) and was registered in US Clinical Trial registry. 


\section{Objectives}

The objective was to evaluate the effectiveness of cervical interlaminar epidural injections with local anesthetic or local anesthetic with steroids, with pain relief and functional status improvement in managing chronic neck and upper extremity pain secondary to cervical post-surgery syndrome.

\section{Trial design}

A randomized active-controlled trial of fluoroscopic cervical interlaminar epidural injections. Patients were assigned into 2 groups with equal assignment to a local anesthetic group (Group I) and a local anesthetic and steroid group (Group II).

\section{Participants}

All participants were recruited from the author's practice and were provided with the protocol and informed consent with detailed descriptions of all aspects of the study and withdrawal process.

All the patients were assessed with demographic data, radiologic investigations, physical examination, pain rating scores using the numeric rating scale (NRS), work status, and functional status assessment evaluated by the Neck Disability Index (NDI), and history of coexisting disease(s).

\section{Inclusion criteria}

The patients with cervical post-surgery syndrome with a history of surgery, performed at least one year prior to the enrollment, and 18 years of age, with a history of chronic function-limiting neck and upper extremity pain of at least 6 months' duration, were included. All the patients had to have undergone conservative modalities including drug therapy, physical therapy, and a structured exercise program with lack of response or inadequate response.

Patients with uncontrollable or unstable opioid use, uncontrolled medical illness, any condition that could interfere with outcomes assessment, those with uncontrolled psychiatric disorders, and pregnant or lactating women, were excluded. In addition, those patients with a history or potential for adverse reactions to local anesthetics or steroids were also excluded.

\section{Interventions}

All patients received cervical interlaminar epidural injections under fluoroscopic guidance with the epidural space identified by the loss of resistance technique and injection of contrast medium. Procedures were performed by one physician (LM) in an operating room, in an ambulatory surgery center, with appropriate sterile preparation.

The epidural space was entered with an 18 gauge, 9 $\mathrm{cm}$ long Tuohy needle. The entry into the epidural space was between $\mathrm{C} 7$ and $\mathrm{T} 1$ to $\mathrm{C} 5$ and C6. All procedures were performed below the scar if patients have undergone posterior cervical laminectomy.

After confirmation of the appropriate position in the epidural space without subarachnoid or intravascular placement, an injection of $5 \mathrm{~mL}$ of preservative free lidocaine hydrochloride $0.5 \%$ in was given in Group I, whereas in Group II $4 \mathrm{~mL}$ of preservative free lidocaine mixed with $6 \mathrm{mg}$ of betamethasone were administered.

\section{Additional interventions}

All patients were provided with an option to receive additional treatments with return of pain as assigned to their group. Patients were also unblinded on request, or if an emergency arose.

\section{Co-interventions}

An overwhelming majority of the patients prior to enrollment were receiving non-opioid analgesics, adjuvant analgesics, opioids, and treatment through a structured exercise program, alone or in combination. The patients with significant improvement in pain and functional status were given reduced amounts and frequency of opioids or stopped, whereas structured exercise programs, work, and activities were continued.

\section{Outcomes}

Outcomes were measured at 3, 6, 12, 18, and 24 months with inclusion of NRS, NDI, and work status. At least 50\% pain relief associated with 50\% improvement in NDI was defined as significant. The value and reliability of NRS and NDI have been published [28].

The employability of individuals was based on their 
prior status of either unemployment, employment on part-time basis, or no employment due to pain. However, all the patients enrolled in the trial who chose not to work, were retired, or were homemakers not working outside, but not due to pain, were not considered to be employable.

\section{Sample size}

The sample size calculations with a 0.052 -sided significance level, a power of $80 \%$, and an allocation ratio of $1: 1$, yielded inclusion of 55 patients in each group [29]. Further, with an allowance of a $10 \%$ attrition and noncompliance rate, 60 patients were considered as ideal.

The sample size calculation was based on significant pain relief and functional status improvement, as well as experience from previous studies of interventional techniques [22,23].

An interim analysis was planned at the completion of one year for the available sample, and was published with a total of 56 patients [22].

\section{Randomization}

From a sample of 116 patients who were willing to participate in the trial and had signed informed consent, $58 \mathrm{pa}-$ tients were randomly allocated to one of the 2 groups.

\section{Sequence generation}

A computer-generated random allocations sequence by simple randomization was utilized, generated by the statistician (VS).

\section{Allocation concealment}

An operating room nurse, assisting with the procedure, randomized the patients and prepared the drugs appropriately.

\section{Implementation}

All the eligible participants meeting the inclusion criteria were invited to enroll in the study. Only the participants understanding the protocol and outcome assessments and signing the informed consent were included. The enrollment was carried out by one of the 3 study coordinators.

\section{Blinding (masking)}

Participants and those administering the interventions were blinded to the group assignments. Outcomes were assessed using questionnaires by the research coordinator. All others were blinded.

\section{Statistical methods}

Data analyses were carried out using the Statistical Package for Social Sciences version 22 (IBM Corporation, Armonk, NY). Categorical and continuous data comparison, Chi-squared test (Fisher's exact test where necessary) and $t$ test were performed. Because the outcome measures of the patients were measured at 6 points in time, a repeated measures analysis of variance was performed.

Univariate analyses of variance with gender, body mass index (BMI), and baseline ODI score as covariates were performed on the reduction in average pain scores and functional improvements between groups.

A $P$ value of less than 0.05 was considered as statistically significant.

\section{Intent-to-treat-analysis}

An intent-to-treat-analysis was performed. Either the last follow-up data or initial data were utilized in patients who dropped out of the study where no other data were available. Sensitivity analysis was performed utilizing best case, worse case, and last follow-up data.

\section{RESULTS}

\section{Participant flow}

Fig. 1 shows participant flow with descriptions of patient assessments, randomization, follow-up, and dropouts.

\section{Recruitment}

Patients were recruited from a period beginning February 2008 and lasting through December 2012. Outcomes were completed at the end of 2 years in 2014 . 


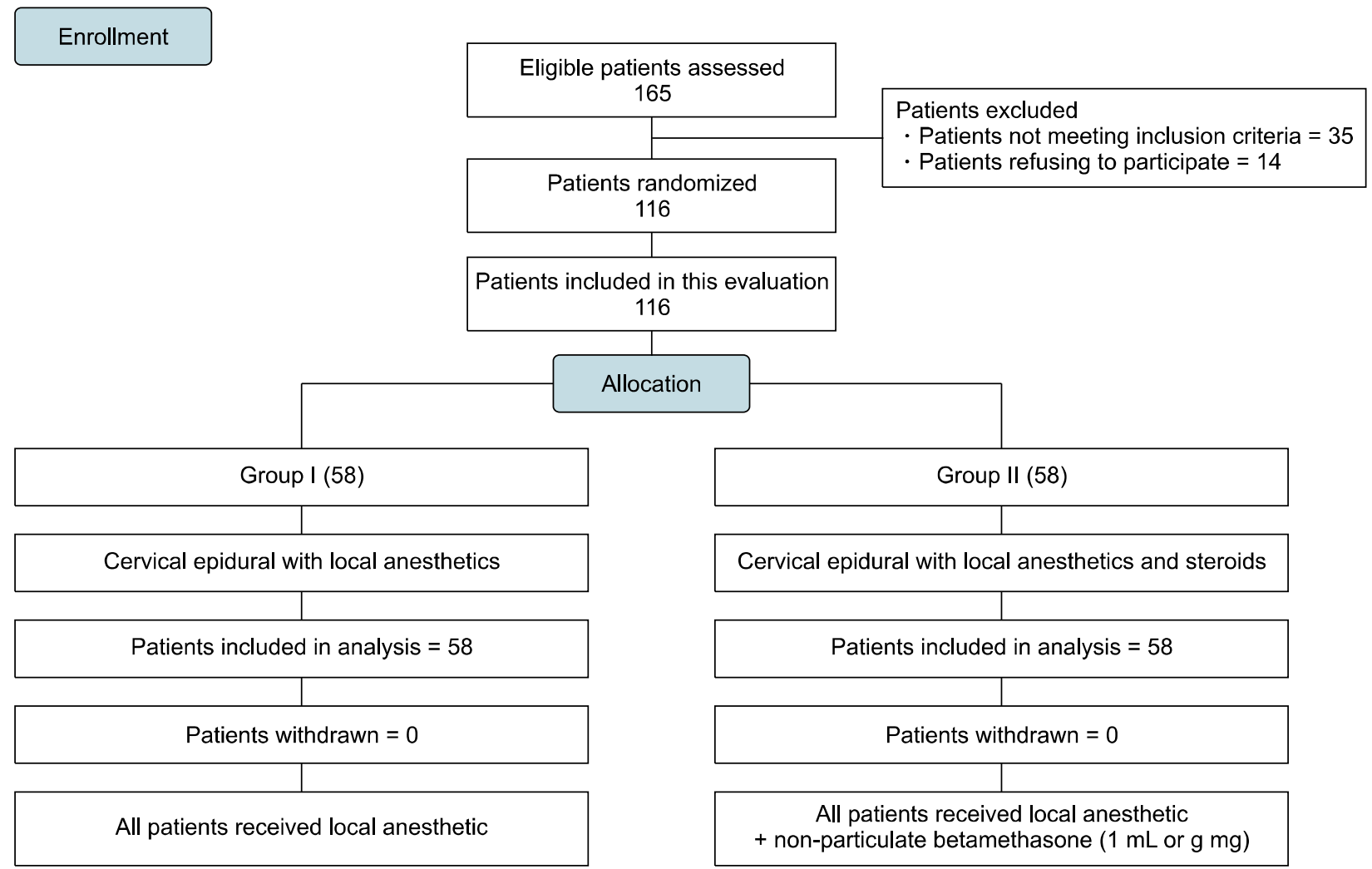

Follow-up \& analysis

12 months

- $86 \%(50 / 58)$ patients available for follow-up

. $100 \%(58)$ patients included in analysis

24 months

- $81 \%(47 / 58)$ patients available for follow-up

- $100 \%$ (58) patients included in analysis

12 months

- $96 \%(56 / 58)$ patients available for follow-up

. $100 \%(58)$ patients included in analysis

Fig. 1. Schematic presentation as per CONSORT of patient flow at 2-years follow-up.

\section{Baseline data}

Baseline demographic characteristics including gender, neck pain distribution, type of surgical interventions, number of surgical interventions, Numeric Rating Scale (NRS) scores, and Neck Disability Index (NDI) scores, which are shown in Table 1. No differences were found in any of the variables except gender, weight, height, and body mass index (BMI). These differences reflect the population distribution of the practice, as does the acceptance of offered treatment, which was female dominant.

\section{Analysis of data}

\section{1) Numbers analyzed}

Fig. 1 provides a schematic illustration of patient flow. A total of 116 patients completed the two-years follow-up, with 58 patients in each group. The data were available for the majority of the included patients.

Intent-to-treat analysis was performed due to unavailable data at 3 months for 1 patient, 7 patients at 6 months, 9 patients at 12 months, 11 patients at 18 and 24 months in Group I, and at 3 months for 1 patient, 4 patients at 6 months, 3 patients at 12 months, and 9 patients 
Table 1. Baseline Demographic Characteristics

\begin{tabular}{|c|c|c|c|c|}
\hline & & Group 1 (58) & Group II (58) & $P$ value \\
\hline \multirow[t]{2}{*}{ Gender } & Male & $28 \%(16)$ & $59 \%(34)$ & $0.001 *$ \\
\hline & Female & $72 \%(42)$ & $41 \%(24)$ & \\
\hline Age & Mean \pm SD & $49.3 \pm 9.6$ & $48.4 \pm 10.2$ & 0.635 \\
\hline Weight & Mean $\pm S D$ & $192.8 \pm 48.2$ & $172.9 \pm 39.5$ & $0.016^{*}$ \\
\hline Height & Mean $\pm S D$ & $65.4 \pm 3.7$ & $67.8 \pm 4.6$ & $0.003^{*}$ \\
\hline Body mass Index (BMI) & Mean $\pm S D$ & $31.6 \pm 7.3$ & $26.3 \pm 5.1$ & $0.001 *$ \\
\hline Duration of pain (months) & Mean $\pm S D$ & $127.8 \pm 84.2$ & $123.5 \pm 96.7$ & 0.801 \\
\hline \multirow[t]{2}{*}{ Onset of the pain } & Gradual & $55 \%(32)$ & $62 \%(36)$ & 0.286 \\
\hline & Injury & $45 \%(26)$ & $38 \%(22)$ & \\
\hline \multirow[t]{4}{*}{ Neck pain distribution } & Neck pain only & $14 \%(8)$ & $14 \%(8)$ & 0.769 \\
\hline & Neck pain worse than upper extremity & $53 \%(31)$ & $57 \%(33)$ & \\
\hline & Upper extremity than neck pain & $5 \%(3)$ & $8 \%(5)$ & \\
\hline & Both equal & $28 \%(16)$ & $21 \%(12)$ & \\
\hline \multirow[t]{2}{*}{ Surgical Interventions } & Anterior fusion & $91 \%(53)$ & $90 \%(52)$ & 1.000 \\
\hline & Posterior fusion or laminectomy & $9 \%(5)$ & $10 \%(6)$ & 1.000 \\
\hline \multirow[t]{3}{*}{ Number of surgeries } & One & $83 \%(48)$ & $79 \%(46)$ & 0.701 \\
\hline & Two & $14 \%(8)$ & $14 \%(8)$ & \\
\hline & $>$ Two & $3 \%(2)$ & $7 \%(4)$ & \\
\hline Numeric rating score & Mean $\pm S D$ & $8.0 \pm 0.98$ & $8.0 \pm 0.93$ & 0.846 \\
\hline Neck disability index & Mean $\pm S D$ & $30.4 \pm 4.4$ & $30.0 \pm 5.5$ & 0.640 \\
\hline
\end{tabular}

*indicates significant difference between groups.

at 18 and 24 months in Group II.

\section{2) Analysis of sensitivity}

Utilizing the last follow-up score, best-case scenario, and worst-case scenario, a sensitivity analysis with changes in the numeric pain scores was performed. No significant differences were found, and therefore the intent-to-treat analysis using the last follow-up visit was performed.

\section{Outcomes}

\section{1) Pain relief and functional assessment}

The NRS and NDI scores are shown in Table 2. NDI and pain scores changed significantly from baseline follow-up at $3,6,12,18$, and 24 months in both groups, but there were no significant differences between the groups.

The percentage of patients showing significant improvement with a reduction in NRS and NDI of $50 \%$ or more from baseline are illustrated in Fig. 2. This data also shows that there was a somewhat better proportion of patients with a response when only responsive participants were analyzed compared to all participants. Obviously, the patients in the nonresponsive group of participants were nonresponsive.

\section{2) Employment characteristics}

Among the individuals who were eligible for employment, which was less than $25 \%$, there was no significant change in employment.

\section{(1) Changes in weight}

At the end of 2 years, in Group I, 48\% of the patients lost weight compared to $43 \%$ in Group II. On the other hand, $33 \%$ of the patients in Group I and $45 \%$ of the patients in Group II gained weight.

\section{(2) Covariates of BMI, gender, and baseline ODI score}

Univariate analyses of variance with BMI, gender, and baseline NDI as a covariate revealed no significant differences in average pain and NDI scores between Groups I and II. 
Table 2. Comparison of Numeric Rating Scale for Pain and Neck Disability Index Score Summaries at Six Time Points

\begin{tabular}{|c|c|c|c|c|}
\hline \multirow[b]{2}{*}{ Time points } & \multicolumn{2}{|c|}{ Numeric pain rating score Mean $\pm S D$} & \multicolumn{2}{|c|}{ Neck disability index Mean \pm SD } \\
\hline & Group I (58) & Group ॥ (58) & Group I (58) & Group II (58) \\
\hline Baseline & $8.0 \pm 0.98$ & $8.0 \pm 0.93$ & $30.4 \pm 4.4$ & $30.0 \pm 5.5$ \\
\hline 3 months & $3.9^{*} \pm 1.34(72 \%)$ & $3.9^{*} \pm 1.41(74 \%)$ & $16.4^{*} \pm 6.01(67 \%)$ & $16.1^{*} \pm 7.07(74 \%)$ \\
\hline 6 months & $3.8^{*} \pm 1.29(76 \%)$ & $3.7^{\star} \pm 1.47(76 \%)$ & $15.7^{\star} \pm 5.87(71 \%)$ & $15.4^{*} \pm 6.98(76 \%)$ \\
\hline 12 months & $3.7^{*} \pm 1.33(78 \%)$ & $3.8^{*} \pm 1.56(71 \%)$ & $15.1^{*} \pm 5.95(74 \%)$ & $15.0^{*} \pm 6.67(72 \%)$ \\
\hline 18 months & $3.7^{*} \pm 1.48(76 \%)$ & $3.8^{*} \pm 1.53(72 \%)$ & $14.8^{*} \pm 6.14(74 \%)$ & $14.9^{*} \pm 6.61(72 \%)$ \\
\hline 24 months & $3.7^{\star} \pm 1.58(71 \%)$ & $3.8^{*} \pm 1.57(71 \%)$ & $14.7^{\star} \pm 6.29(71 \%)$ & $14.9^{*} \pm 6.64(71 \%)$ \\
\hline Group difference & \multicolumn{2}{|c|}{0.933} & \multicolumn{2}{|c|}{0.972} \\
\hline Baseline vs follow-up points & \multicolumn{2}{|c|}{0.001} & \multicolumn{2}{|c|}{0.001} \\
\hline Group by time interaction ${ }^{\#}$ & \multicolumn{2}{|c|}{0.794} & \multicolumn{2}{|c|}{0.906} \\
\hline
\end{tabular}

Percentages in parenthesis illustrates proportion with significant pain relief $(\geq 50 \%)$ from baseline. *indicates significant difference with baseline values $(P<0.01)$ with in the group. ${ }^{\#}$ Group by Time Interaction-There was no significant difference between groups at 3 months, 6 months, 12 months, 18 months and 24 months.

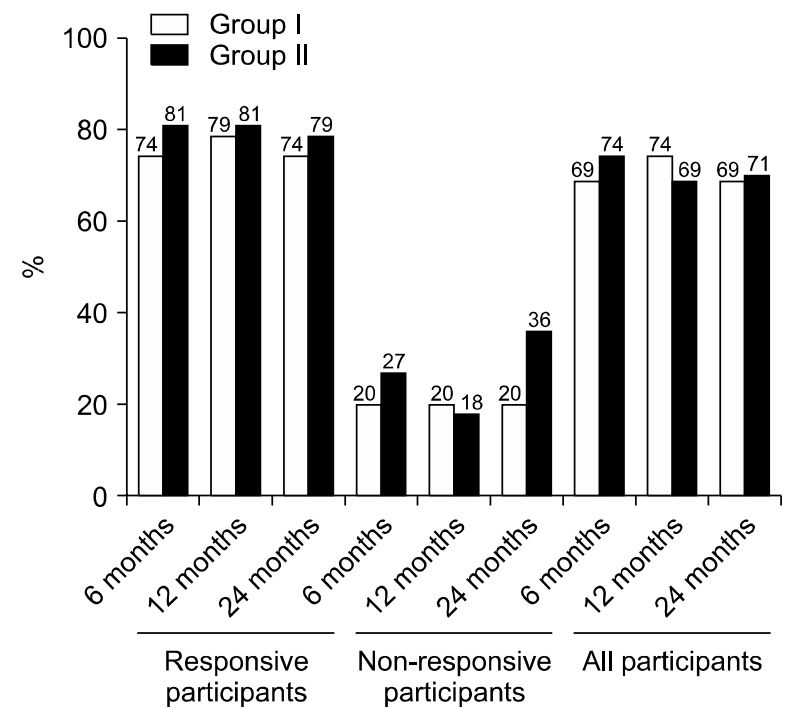

Fig. 2. Proportion of patients with significant reduction in numeric rating score and neck disability index $(\geq 50 \%$ reduction from baseline).

\section{(3) Characteristics of therapeutic procedural}

Epidural entry was performed between $\mathrm{C} 7$ and $\mathrm{T} 1$ in 20\% of the patients, between $\mathrm{C} 6$ and $\mathrm{C} 7$ in $56 \%$ of the patients, and between C5 and C6 in 24\% of the patients. If a patient obtained consistent relief lasting at least 3 weeks with 2 initial injections, the initial therapy was considered as responsive, and the remainder were considered nonresponsive.

Table 3 illustrates the characteristics of the therapeutic procedures. Average relief after 2 years showed no significant differences: $65.6 \pm 37.8$ weeks in Group I and $59.4 \pm 34.2$ weeks in Group II. The average number of injections per 2 years was $5.6 \pm 2.7$ in Group I and $5.2 \pm$ 2.5 in Group II. However, when patients were separated into responsive and non-responsive groups, the average number of injections per year was $5.9 \pm 2.5$ in Group I and $5.6 \pm 2.4$ in Group II in the responsive participants, and 2.6 for Group I and 3.2 for Group II in the nonresponsive participants. In the responsive participants, the average total relief in Group I was 70.3 weeks compared to 66.7 weeks in Group II. By further comparison, the total relief was 16 weeks in Group I and 28.6 weeks for the nonresponsive patients in Group II.

\section{3) Adverse events}

There were a total of 627 cervical epidural procedures performed in this study. Of these, there were 12 subarachnoid punctures and 18 intravascular entries. No headaches or other complications were recorded.

\section{DISCUSSION}

This examination of the 2-year results of a randomized active controlled trial, with assessment of the effectiveness of fluoroscopic cervical interlaminar epidural injections in managing chronic neck pain in post cervical surgery syndrome included 116 patients, and showed significant improvement with pain relief and functional status improvement in $69 \%$ of the patients in Group I with local anesthetic 
Table 3. Therapeutic Procedural Characteristics with Procedural Frequency, Average Relief Per Procedure, and Average Total Relief in Weeks Over a Period of 1 -year

\begin{tabular}{|c|c|c|c|c|c|c|}
\hline & \multicolumn{2}{|c|}{ Responsive participants } & \multicolumn{2}{|c|}{ Non-responsive participants } & \multicolumn{2}{|c|}{ All participants } \\
\hline & $\begin{array}{c}\text { Group I } \\
(53)\end{array}$ & $\begin{array}{c}\text { Group II } \\
(47)\end{array}$ & $\begin{array}{l}\text { Group I } \\
(5)\end{array}$ & $\begin{array}{l}\text { Group II } \\
\text { (11) }\end{array}$ & $\begin{array}{c}\text { Group I } \\
(58)\end{array}$ & $\begin{array}{c}\text { Group II } \\
(58)\end{array}$ \\
\hline Average number of procedures for one year & $3.7 \pm 1.0$ & $3.9 \pm 1.1$ & $1.8 \pm 1.3$ & $2.6 \pm 1.2$ & $3.6 \pm 1.2$ & $3.7 \pm 1.2$ \\
\hline $\begin{array}{l}\text { Average number of procedures for two } \\
\text { years }\end{array}$ & $5.9 \pm 2.5$ & $5.6 \pm 2.4$ & $2.6 \pm 3.0$ & $3.2 \pm 2.1$ & $5.6 \pm 2.7$ & $5.2 \pm 2.5$ \\
\hline $\begin{array}{l}\text { Average relief per procedure for initial two } \\
\text { procedures in weeks }\end{array}$ & $8.8 \pm 11.1$ & $9.4 \pm 14.9$ & $0.7 \pm 0.8$ & $0.7 \pm 0.7$ & $8.2 \pm 10.9$ & $8.0 \pm 14.0$ \\
\hline $\begin{array}{l}\text { Average relief per procedure after initial } \\
\text { two procedures }\end{array}$ & $13.6 \pm 7.1$ & $13.2 \pm 6.3$ & $12.5 \pm 0.8$ & $18.8 \pm 16.7$ & $13.6 \pm 6.9$ & $13.7 \pm 7.8$ \\
\hline Average relief per procedure & $12.0 \pm 8.9$ & $11.9 \pm 10.4$ & $6.1 \pm 6.2$ & $9.0 \pm 14.3$ & $11.8 \pm 8.9$ & $11.5 \pm 10.9$ \\
\hline Average total relief for one year (weeks) & $38.1 \pm 15.4$ & $41.2 \pm 13.3$ & $6.0 \pm 11.7$ & $11.0 \pm 13.5$ & $35.3 \pm 17.6$ & $35.5 \pm 17.9$ \\
\hline Average total relief for two year (weeks) & $70.3 \pm 34.9$ & $66.7 \pm 29.5$ & $16.0 \pm 34.0$ & $28.6 \pm 36.9$ & $65.6 \pm 37.8$ & $59.4 \pm 34.2$ \\
\hline
\end{tabular}

alone, and $71 \%$ of the patients in Group II with local anesthetic and steroids.

Significant improvement was defined as improvement of pain relief and functional status of at least 50\%. Additionally, patients who were responsive to the initial 2 epidural injections, and therefore were labeled as "responsive participants", also showed a slightly higher outcome, with a success rate of $74 \%$ with local anesthetic alone and $79 \%$ with local anesthetic and steroids, compared to $69 \%$ with local anesthetic alone and $71 \%$ with local anesthetic and steroids at the end of 24 months.

Over the 2-year period, the overall number of procedures were $5.6 \pm 2.7$ in Group I and $5.2 \pm 2.5$ in Group II. Also, the results showed an average relief of approximately $13.6 \pm 6.9$ weeks in the local anesthetic only group and $13.7 \pm 17.8$ weeks in the group with local anesthetic and steroids following the initial 2 procedures. Nevertheless, the overall relief over a period of 2 years ranged from $11.5 \pm 10.9$ weeks in patients receiving local anesthetic with steroids to $11.8 \pm 8.9$ weeks in patients receiving local anesthetic alone. The overall results showed that patients received $65.6 \pm 37.8$ weeks of relief over a period of 2 years in patients receiving local anesthetic alone, compared to $59.4 \pm 34.2$ weeks in patients receiving local anesthetic and steroids.

Interestingly, in patients who were responsive, the response was $70.3 \pm 34.9$ weeks in Group I with local anesthetic alone and $66.7 \pm 29.5$ weeks in Group II with patients receiving local anesthetic with steroids. Of importance, this study showed no significant difference whether steroids were used or not with local anesthetic, and these results are similar to multiple other active controlled trials comparing local anesthetic alone with local anesthetic and steroids in the cervical and lumbar spine [23,30-33], and somewhat superior to the results of caudal epidural injections in lumbar central stenosis [34] and lumbar post-surgery syndrome [35].

Given the scarcity of literature studying the role of interlaminar epidural injections in the cervical spine in general, and specifically regarding post-cervical surgery syndrome, to our knowledge, this is the only controlled trial. When compared to the outcomes of the preliminary report, the results at the end of 2 years were very similar [22].

Additionally, there is also a general scarcity of studies performed in appropriate settings with a design that incorporates the proper definition of placebo, utilizes fluoroscopy, and provides repeat interventions when medically necessary and at appropriate intervals. To the contrary, even in the cervical spine, there are multiple reports of epidural injections performed without fluoroscopy or with limited applicability to practical settings. But most importantly, this study provides information on the medical necessity to continue these procedures by identifying their responsiveness to the first 2 procedures by categorizing them into responsive or nonresponsive groups of patients. In this study, the nonresponsive patients showed significantly less pain relief even though, ironically, the average relief per injection in these few patients was higher than in the responsive patients (Table 3).

These factors provide the generalizability of this eval- 
uation to interventional pain management settings. Not only is this the first study performed in post cervical surgery syndrome patients, but also was performed under fluoroscopy as an active controlled trial in the setting of a private practice. There is an abundance of literature supporting pragmatic or practical clinical trials, with active controls measuring effectiveness with more appropriate applications in clinical acumen, rather than true placebo controlled or explanatory trials measuring efficacy [36].

Recently, in fact, the Food and Drug Administration (FDA) has defined the use of real world data in regulatory decision-making [37]. They defined real world evidence as the analysis of real world data sources in a study designed with a high degree of pragmatism, regardless of study type. Additionally, they reported that one of the attractions of real world evidence is that the current clinical trial enterprise, based largely on randomized clinical trials, is time consuming, burdensome, and expensive [37]. Also apart from being a potential cost saver, the real world evidence is, by its nature, highly pragmatic, and would therefore be expected to be more generalizable. Furthermore, they also reported that certain evidence generated from randomized controlled trials (RCTs) within a health care system are also considered to be sources of real world evidence. And then, there have been extensive discussions in reference to appropriate use of placebos and inappropriate assignment of local anesthetic injections into placebo groups in recent years, leading to inappropriate conclusions $[23,24]$.

Thus, the practical applications of this current trial are crucial since this assessment utilized an active control design with 2 commonly used drugs, namely local anesthetic and local anesthetic with steroids [38]. This study also has the additional advantages of repeating cervical interlaminar epidural injections based on multiple clinical factors, including increasing pain levels and deterioration in functional status, while at the same time not being bound to a routine protocol of providing 3 injections or being limited to 3 procedures, or limiting them to one or 2 procedures as in other studies [23,24,30-33]. Not only that, but this study also provides a basis for discontinuation of interventions when patients do not respond to the first 2 procedures.

Nevertheless, this study may be criticized or considered as deficient due to lack of a placebo group. The issue of placebo groups has been extensively addressed in multi- ple previously published studies [23,24,30-37] in which pragmatic trials and the real world evidence were defined, as well as the risks of classifying active treatments into placebo controls, leading to inappropriate conclusions. Potentially another disadvantage of this study may be the lack of blinding in regard to the injectate. In approximately half of the procedures, this was achieved with clear solutions available. Differing solutions were received by the remaining half. However, these patients were mixed with all other patients and so there was no identification to the physician performing the procedure that the patients were in the study. Still another limitation is that the study was conducted in a single center.

The final arguments still made are that there is no significant anti-inflammatory activity with local anesthetics, and therefore the results may not be valid based on acute pain mechanisms. The mechanisms of action, however, of not only local anesthetics, but also of steroids, have been well described, with similar mechanisms and potentially similar effects of similar duration for both [24,30-35,39-47]. Emerging evidence shows that local anesthetics may be equally as effective as steroids in managing spinal pain [23,24,30-35,39,40]. Further, the reports of multiple pathophysiological mechanisms invoking chronic pain with noxious peripheral stimulation, sensitization of the pain pathways by excess nociception, and complex central responses, including hyperalgesia or wind up from excess release of neurotransmitters [39] resulting in an increase in nociceptive sensitization of the nervous system $[48,49]$, along with phenotype changes which are considered as part of the neuronal plasticity [46,48-50], have been suppressed by local anesthetics. These anti-inflammatory long-term effects of local anesthetics are similar to the long-term anti-inflammatory properties of corticosteroids by way of the inhibition of prostaglandin synthesis and a decrease in regional levels of inflammatory mediators [39,43,50-52]. Consequently, based on the overwhelming literature, once again, this study of the effectiveness of cervical interlaminar epidural injections with or without steroids with local anesthetic, in managing post cervical surgery syndrome, reinforces the previous findings.

In conclusion, the results of this randomized controlled trial of fluoroscopic cervical interlaminar epidural injections in chronic neck pain, secondary to post cervical surgery syndrome, showed significant pain relief and functional 
status improvement of $50 \%$ or more in $69 \%$ or $71 \%$ of the patients at 2-year follow-up with local anesthetic with or without steroids. The study was performed in a practical private practice setting, with procedures performed in a sterile setting in an operating room with repeat injections provided, based on the medical necessity of increasing pain levels and decreasing functional status below a 50\% level. There was no significant difference in the outcomes whether local anesthetics were administered alone or with steroids.

\section{REFERENCES}

1. Nordin M, Randhawa K, Torres P, Yu H, Haldeman S, Brady $\mathrm{O}$, et al. The global spine care initiative: a systematic review for the assessment of spine-related complaints in populations with limited resources and in low- and middle-income communities. Eur Spine J 2018 [in press].

2. Dieleman $\mathrm{J}$, Baral R, Birger M, Bui AL, Bulchis A, Chapin A, et al. US spending on personal health care and public health, 1996-2013. JAMA 2016; 316: 2627-46.

3. Dieleman JL, Squires E, Bui AL, Campbell M, Chapin A, Hamavid $\mathrm{H}$, et al. Factors associated with increase in US health care spending, 1996-2013. JAMA 2017; 318: 1668-78.

4. Murray CJ, Atkinson C, Bhalla K, Birbeck G, Burstein R, Chou D, et al. The state of US health, 1990-2010: burden of diseases, injuries, and risk factors. JAMA 2013; 310: 591-608.

5. Mokdad AH, Ballestros K, Echko M, Glenn S, Olsen HE, Mullany E, et al. The state of US health, 1990-2016: burden of diseases, injuries, and risk factors among US states. JAMA 2018; 319: 1444-72.

6. Leboeuf-Yde C, Nielsen J, Kyvik KO, Fejer R, Hartvigsen J. Pain in the lumbar, thoracic or cervical regions: do age and gender matter? a population-based study of 34,902 Danish twins 20-71 years of age. BMC Musculoskelet Disord 2009; 10: 39 .

7. Hoy D, March L, Woolf A, Blyth F, Brooks P, Smith E, et al. The global burden of neck pain: estimates from the global burden of disease 2010 study. Ann Rheum Dis 2014; 73: 1309-15.

8. Manchikanti L, Kaye AM, Knezevic NN, McAnally H, Slavin K. Trescot AM, et al. Responsible, safe, and effective prescription of opioids for chronic non-cancer pain: American society of interventional pain physicians (ASIPP) guidelines. Pain Physician 2017; 20: S3-92.

9. Manchikanti L, Pampati V, Hirsch JA. Utilization of interventional techniques in managing chronic pain in medicare population from 2000 to 2014: an analysis of patterns of utilization. Pain Physician 2016; 19: E531-46.

10. Manchikanti L, Soin A, Mann DP, Bakshi S, Pampati V, Hirsch JA. Reversal of growth of utilization of interventional techniques in managing chronic pain in medicare population post affordable care act. Pain Physician 2017; 20: 551-67.

11. Manchikanti L, Singh V, Hirsch JA. Facility payments for interventional pain management procedures: impact of proposed rules. Pain Physician 2016; 19: E957-84.

12. Manchikanti L, Kaye AD, Hirsch JA. Proposed medicare physician payment schedule for 2017: impact on interventional pain management practices. Pain Physician 2016; 19: E935-55.

13. Manchikanti L, Pampati V, Hirsch JA. Retrospective cohort study of usage patterns of epidural injections for spinal pain in the US fee-for-service Medicare population from 2000 to 2014. BMJ Open 2016; 6: e013042.

14. Bakhsheshian J, Mehta VA, Liu JC. Current diagnosis and management of cervical spondylotic myelopathy. Global Spine J 2017; 7: 572-86.

15. Derman PB, Lampe LP, Hughes AP, Pan TJ, Kueper J, Girardi FP, et al. Demographic, clinical, and operative factors affecting long-term revision rates after cervical spine arthrodesis. J Bone Joint Surg Am 2016; 98: 1533-40.

16. Gutman G, Rosenzweig DH, Golan JD. Surgical treatment of cervical radiculopathy: meta-analysis of randomized controlled trials. Spine (Phila Pa 1976) 2018; 43: E365-72.

17. Patil PG, Turner DA, Pietrobon R. National trends in surgical procedures for degenerative cervical spine disease: 19902000. Neurosurgery 2005; 57: 753-8.

18. Leavitt SB. NSAID dangers may limit pain-relief options. Pain-topics news/research updates [Internet]. 2010 [cited 2010 Mar 14]. Available at http://updates.pain-topics.org/ 2010/03/nsaid-dangers-may-limit-pain-relief.html.

19. Moore A, Wiffen P, Kalso E. Antiepileptic drugs for neuropathic pain and fibromyalgia. JAMA 2014; 312: 182-3.

20. Manchikanti L, Hirsch JA, Kaye AD, Boswell MV. Cervical zygapophysial (facet) joint pain: effectiveness of interventional management strategies. Postgrad Med 2016; 128: 54-68.

21. Shamji MF, Cook C, Pietrobon R, Tackett S, Brown C, Isaacs RE. Impact of surgical approach on complications and resource utilization of cervical spine fusion: a nationwide perspective to the surgical treatment of diffuse cervical spondylosis. Spine J 2009; 9: 31-8.

22. Manchikanti L, Malla Y, Cash KA, McManus CD, Pampati V. Fluoroscopic cervical interlaminar epidural injections in managing chronic pain of cervical postsurgery syndrome: preliminary results of a randomized, double-blind, active control trial. Pain Physician 2012; 15: 13-25.

23. Kaye AD, Manchikanti L, Abdi S, Atluri S, Bakshi S, Benyamin $\mathrm{R}$, et al. Efficacy of epidural injections in managing chronic 
spinal pain: a best evidence synthesis. Pain Physician 2015; 18: E939-1004.

24. Manchikanti L, Knezevic NN, Boswell MV, Kaye AD, Hirsch JA. Epidural injections for lumbar radiculopathy and spinal stenosis: a comparative systematic review and meta-analysis. Pain Physician 2016; 19: E365-410.

25. Manchikanti L, Pampati V, Benyamin RM, Hirsch JA. Cost utility analysis of lumbar interlaminar epidural injections in the treatment of lumbar disc herniation, central spinal stenosis, and axial or discogenic low back pain. Pain Physician 2017; 20: 219-28.

26. Manchikanti L, Pampati V, Kaye AD, Hirsch JA. Therapeutic lumbar facet joint nerve blocks in the treatment of chronic low back pain: cost utility analysis based on a randomized controlled trial. Korean J Pain 2018; 31: 27-38.

27. Manchikanti L, Pampati V, Kaye AD, Hirsch JA. Cost utility analysis of cervical therapeutic medial branch blocks in managing chronic neck pain. Int J Med Sci 2017; 14: 1307-16.

28. Cleland JA, Childs JD, Whitman JM. Psychometric properties of the neck disability index and numeric pain rating scale in patients with mechanical neck pain. Arch Phys Med Rehabil 2008; 89: 69-74.

29. Browner WS, Newman TB, Cummings SR, Hulley SB. Estimating sample size and power. In: Designing clinical research: an epidemiologic approach. 2nd ed. Edited by Hulley SB, Cummings SR, Browner WS, Grady D, Hearst N, Newman TB. Philadelphia, PA, Lippincott Williams \& Wilkins. 2001, pp 65-84.

30. Zhai J, Zhang L, Li M, Tian Y, Zheng W, Chen J, et al. Epidural injection with or without steroid in managing chronic low back and lower extremity pain: a meta-analysis of ten randomized controlled trials. Int J Clin Exp Med 2015; 8: 8304-16.

31. Manchikanti L, Cash KA, Pampati V, Wargo BW, Malla Y. A randomized, double-blind, active control trial of fluoroscopic cervical interlaminar epidural injections in chronic pain of cervical disc herniation: results of a 2-year follow-up. Pain Physician 2013; 16: 465-78.

32. Manchikanti L, Cash KA, Pampati V. Malla Y. Two-year follow-up results of fluoroscopic cervical epidural injections in chronic axial or discogenic neck pain: a randomized, double-blind, controlled trial. Int J Med Sci 2014; 11: 309-20.

33. Manchikanti L, Malla Y, Cash KA, McManus CD, Pampati V. Fluoroscopic epidural injections in cervical spinal stenosis: preliminary results of a randomized, double-blind, active control trial. Pain Physician 2012; 15: E59-70.

34. Manchikanti L, Cash KA, McManus CD, Pampati V, Fellows B. Results of 2-year follow-up of a randomized, double-blind, controlled trial of fluoroscopic caudal epidural injections in central spinal stenosis. Pain Physician 2012;
15: $371-84$.

35. Manchikanti L, Singh V, Cash KA, Pampati V, Datta S. Fluoroscopic caudal epidural injections in managing post lumbar surgery syndrome: two-year results of a randomized, double-blind, active-control trial. Int J Med Sci 2012; 9: 582-91.

36. Tunis SR, Stryer DB, Clancy CM. Practical clinical trials: increasing the value of clinical research for decision making in clinical and health policy. JAMA 2003; 290: 1624-32.

37. Sherman RE, Anderson SA, Dal Pan GJ, Gray GW, Gross T, Hunter NL, et al. Real-world evidence - what is it and what can it tell us? N Engl J Med 2016; 375: 2293-7.

38. International conference on harmonisation of technical requirements for registration of pharmaceuticals for human use. ICH harmonised tripartite guideline. Choice of control group and related issues in clinical trials E10 [Internet]. Geneva: ICH Steering Committee; 2000 [cited 2018 May 9]. Available at https://www.ich.org/fileadmin/Public_Web_Site/ ICH_Products/Guidelines/Efficacy/E10/Step4/E10_Guideline. pdf.

39. Pasqualucci A, Varrassi G, Braschi A, Peduto VA, Brunelli A, Marinangeli $F$, et al. Epidural local anesthetic plus corticosteroid for the treatment of cervical brachial radicular pain: single injection versus continuous infusion. Clin J Pain 2007; 23: 551-7.

40. Tachihara H, Sekiguchi M, Kikuchi S, Konno S. Do corticosteroids produce additional benefit in nerve root infiltration for lumbar disc herniation? Spine (Phila Pa 1976) 2008; 33: 743-7.

41. Sato C, Sakai A, Ikeda Y, Suzuki H, Sakamoto A. The prolonged analgesic effect of epidural ropivacaine in a rat model of neuropathic pain. Anesth Analg 2008; 106: 313-20.

42. Song T, Gu K, Wang W, Wang $H$, Yang $Y$, Yang $L$, et al. Prolonged suppression of neuropathic pain by sequential delivery of lidocaine and thalidomide drugs using PEGylated graphene oxide. J Pharm Sci 2015; 104: 3851-60.

43. Byröd G, Otani K, Brisby $H$, Rydevik B, Olmarker $K$. Methylprednisolone reduces the early vascular permeability increase in spinal nerve roots induced by epidural nucleus pulposus application. J Orthop Res 2000; 18: 983-7.

44. Lee HM, Weinstein JN, Meller ST, Hayashi N, Spratt KF, Gebhart GF. The role of steroids and their effects on phospholipase A2. An animal model of radiculopathy. Spine (Phila Pa 1976) 1998; 23: 1191-6.

45. Hayashi N, Weinstein JN, Meller ST, Lee HM, Spratt KF, Gebhart GF. The effect of epidural injection of betamethasone or bupivacaine in a rat model of lumbar radiculopathy. Spine (Phila Pa 1976) 1998; 23: 877-85.

46. Pennypacker KR, Hong JS, McMillian MK. Implications of prolonged expression of Fos-related antigens. Trends Pharmacol Sci 1995; 16: 317-21. 
47. Johansson A, Hao J, Sjölund B. Local corticosteroid application blocks transmission in normal nociceptive C-fibres. Acta Anaesthesiol Scand 1990; 34: 335-8.

48. Kawakami M, Weinstein JN, Chatani K, Spratt KF, Meller ST, Gebhart GF. Experimental lumbar radiculopathy. Behavioral and histologic changes in a model of radicular pain after spinal nerve root irritation with chromic gut ligatures in the rat. Spine (Phila Pa 1976) 1994; 19: 1795-802.

49. Decosterd I, Woolf CJ. Spared nerve injury: an animal model of persistent peripheral neuropathic pain. Pain 2000; 87 : 149-58.

50. Norimoto M, Ohtori S, Yamashita M, Inoue G, Yamauchi K, Koshi T, et al. Direct application of the TNF-alpha inhibitor, etanercept, does not affect CGRP expression and phenotypic change of DRG neurons following application of nucleus pulposus onto injured sciatic nerves in rats. Spine (Phila Pa 1976) 2008; 33: 2403-8.

51. Genevay S, Finckh A, Payer M, Mezin F, Tessitore E, Gabay $C$, et al. Elevated levels of tumor necrosis factor-alpha in periradicular fat tissue in patients with radiculopathy from herniated disc. Spine (Phila Pa 1976) 2008; 33: 2041-6.

52. Yamashita M, Ohtori S, Koshi T, Inoue G, Yamauchi K, Suzuki $M$, et al. Tumor necrosis factor-alpha in the nucleus pulposus mediates radicular pain, but not increase of inflammatory peptide, associated with nerve damage in mice. Spine (Phila Pa 1976) 2008; 33: 1836-42. 